Article

\title{
Fostering Creativity in the Classroom for High Ability Students: Context Does Matter
}

\author{
Liang See Tan *, Shu Shing Lee, Letchmi Devi Ponnusamy, Elizabeth Ruilin Koh and \\ Keith Chiu Kian Tan \\ National Institute of Education, Nanyang Technological University, 1 Nanyang Walk, Singapore 637616, \\ Singapore; shushing.lee@nie.edu.sg (S.S.L.); letchmi.p@nie.edu.sg (L.D.P.); elizabeth.koh@nie.edu.sg (E.R.K.); \\ keith.tan@nie.edu.sg (K.C.K.T.) \\ * Correspondence: liangsee.tan@nie.edu.sg; Tel.: +65-6219-6254 \\ Academic Editor: Steven I. Pfeiffer \\ Received: 19 August 2016; Accepted: 29 October 2016; Published: 9 November 2016
}

\begin{abstract}
Researchers have argued for the importance of the classroom context in developing students' creative potential. However, the emphasis on a performative learning culture in the classroom does not favour creativity. Thus, how creative potential can be realised as one of the educational goals in the classrooms remains a key question. This study measured creativity across three secondary schools using the Wallach-Kogan Creative Thinking Test (WKCT). A total of 283 students enrolled in the Express programme and 290 students enrolled in the Integrated Programme (IP) volunteered in the study. The same cohort of students took the 38-item WKCT twice; once at the beginning of Secondary One and then at the end of Secondary Three. Four aspects of creativity, namely fluency, flexibility, unusualness, and uniqueness, were investigated. Our analyses showed that (i) IP students showed a greater increase in scores over time when compared to Express students; (ii) when Programme and PSLE (Primary School Leaving Examination) were used to predict creativity scores in a multiple regression, the predictive power of Programme increased from Secondary 1 to Secondary 3 while that of PSLE decreased; and (iii) flexibility scores were more resistant to change than fluency scores. These findings suggest that the classroom context matters and that the removal of high-stakes examination can provide room for the development of creative potential.
\end{abstract}

Keywords: high ability learners; creative thinking; curriculum innovation; quantitative analyses; secondary schools

\section{Introduction}

Creativity is one of the key desired educational outcomes in the 21st century as the world's economic growth is increasingly innovation-driven [1]. Given the demand for the capacity to be creative in the future workforce, schools are expected to teach and assess creativity [2-4]. Besides the economic reasons of promoting creativity [1,5], the justifications for re-kindling the fostering of creativity is seen as a social good both at the individual as well as at the societal level [6]. Since the end of 1990s, there has been growing recognition among educational policymakers that it is imperative to develop creative potential in schools in the UK $[7,8]$ and Singapore. For example, in Singapore, the importance of developing students' creative potential can be seen through the national educational envisioning (e.g., Thinking School Learning Nation, Desired Outcomes of Education), and curriculum policies (e.g., Teach Less Learn More and the 21st Century Competencies). The alignment of educational vision and curriculum policies aims to facilitate the development of creative potential in schools and the determination to nurture creative minds in schools [9]. Almost 20 years have passed and there is limited research evidence of the outcomes of teaching for creativity in Singapore schools. These questions still remain: Can creativity be taught? Does creativity develop over time? 
How can creativity be assessed? All these unanswered questions clearly speak to the complexities and multi-faceted nature of creativity.

Schools are struggling with teaching and assessing creativity [10,11]. This is especially difficult among teachers as creativity is typically understood as generating earth-shattering discoveries or inventions in a specific domain by an outstanding individual. Therefore, there is a need to broaden the conventional understanding of creativity as being relevant not only to an extraordinary class (i.e., the big C) of individuals, but also present in the everyday (i.e., the small C) problem solving tasks [7] as well as the collective creativity seen in groups [12].

Researchers have argued for the importance of classroom context in developing student creative potential $[6,13]$. It is also a longstanding suspicion that high-stakes examinations typically drive students to think in a convergent rather than divergent fashion. Furthermore, the emphasis on performative learning culture in the classroom does not favour creativity. Thus, how students' creative potential can be effectively realised remains a key question.

\section{The Role of Context in Nurturing Creativity}

During the 1990s, due to the development of the approach from social psychology, research into creativity began to focus more on the creativity of ordinary people within aspects of education. Plucker, Beghetto, and Dow (2004) [14] define creativity as "the interaction among aptitude, process, and environment by which an individual or group produces a perceptible product that is both novel and useful as defined within a social context". This definition consists of the four aspects of creativity, that is, the person, process, product, and press (environment) [14]. Besides these four Ps, there are a few lines of inquiry in the creativity literature. Seminal works in creativity research intertwined with and included elements such as personality [15-17], cognition [18-20], and psychodynamics [21,22]. In addition, since 1980s, creativity research using the social psychological perspective has gained momentum. The social psychological perspective recognizes the important role of social structures in fostering individual creativity $[23,24]$. Since then, some significant theories have been put forward in which creativity is seen from a systems perspective $[21,25,26]$, where there is confluence of approaches to the study of creativity.

The role of the context or subject domain has been increasingly emphasized in the creativity literature since the early 1990s. What lies in the environmental milieu is a shared system of cognition, behaviour, and values, in which individuals interact. Lubart (1999) [27] examined creativity across cultures and recognized the importance of environmental milieu. He concluded that there are cultural variations in the creative process as a result of culture being a channel for creativity and the nurturance of creativity. Studies have shown that participating in a learning activity that meets the external needs lower the level of self-determination which may in turn limit the creative performance. In contrast, provision of autonomy and flexibility in the learning environment is more likely to reveal students' potential and produce a better creative performance [28]. Amabile's (1988) [29] model suggests that individual creativity may be affected by even very minor aspects of the immediate social environment. For example, creativity may be impeded where rewards are determined in advance, where there is undue time pressure, over-supervision, competition, or where choices are restricted in terms of approach or working materials, or where evaluation is expected. In the literature, the findings about the exact ages of declines in creativity are mixed. While Torrance (1968) [30] and Urban (1991) [31] documented a drop of creativity during childhood, several researchers noted a decline of creativity scores at 12 years and then a significant increase at 16 years and above [32-34]. As such, Runco and Charles (1997) [35] highlighted the inherent conflict over whether researchers should study performance or the potential for performance. However, Mumford (2003) [10] argued that researchers should study potential as well as performance. Mumford's proposition suggests that measures of potential should be referenced against reasonably realistic creative performance tasks that call for open-ended, generative production. 
Creativity is an everyday human endeavour-whether or not the lessons are designed to elicit creativity, creativity develops in students [36-38]. The movement of nurturing to move beyond individual creativity seems to highlight the imperative role of process and press (i.e., environment). Researchers $[16,17,39]$ show that creativity could be inhibited by several contextual structures in the classroom. Some of these classroom structures include a fixed class schedule [39], constant monitoring of learning, and emphasis on high-stakes examination [40]. Although such structures and practices impede the nurturing of student creativity, we have limited knowledge whether the removal of these unfavourable contextual structures and practices is helpful in nurturing student creativity.

In addition, the lack of clarity in understanding the concept of creativity also results in limited focus on designing learning tasks that foster different aspects of creativity which should be taught in the classroom. This may result in students knowing a laundry list of ideas that belong to the same category of a big idea, but not ideas of alternative categories. Thus, one can hypothesise that students who have more exposure to ideas might have higher scores in fluency in the WKCT, but we have limited knowledge on how flexibility might change over time.

\section{Creativity and Classroom Teaching}

If creativity is one of the desired learning goals, then teacher capacity is pivotal in teaching for creativity. Davies, Jindal-Snape, Collier, Digby, and Howe (2012) [41] reviewed the creativity literature and found pedagogical practice being one of the key environmental features in shaping student creativity. The facilitative pedagogical practices include designing learning tasks that are novel to stimulate students' creativity, planning for a structured yet flexible, self-directed learning experience, setting a mutual respect atmosphere, open dialogue, and collaborative activities. Since pedagogical practice is imperative in the fostering of creativity, researchers are concerned with the tensions faced by teachers in the classroom $[6,8,42]$. Some of the issues faced by teachers include (1) conflicts in policy and practice [43]; (2) tensions in meeting the subject matter requirements and designing learning tasks to foster student creativity [2]; (3) the fear of curricular chaos [8]; and (4) the call for subject-content-based curriculum to teach for creativity [44]. All these dilemmas impede teachers' understanding of creativity, and attitudes towards creativity. For example, Woods and Jeffrey (1996) [45] document ways in which a small group of teachers operate creatively in the face of a wider context which arguably suppresses the creativity of the teaching profession. Craft (1996) [46] explores the perspectives of educators involved in a holistic postgraduate course specifically designed to nurture their own creativity. Fryer (1996) [47] undertook a large-scale survey of teachers' attitudes towards creativity in their daily professional work.

Craft (2003) [6] has called for the need for teachers to know what creativity is all about, so that they know how to teach for creativity. Even as Craft (2003) [6] points to the need for teachers to know more about creativity and the best ways to teach for its growth, others have highlighted important strategies such as the disciplined improvisation [48], creative thinking, action, and behaviour [49], and creative problem solving [50]. Hence, helping teachers develop confidence with the use of such strategies in the classroom is an imperative in today's educational climate.

There has always been increasing interests among policymakers to include creativity in the educational agenda. In the United Kingdom, the Plowden Report (1967) [51] and the National Advisory Group for Creative and Cultural Education in the review of the National Curriculum $[52,53]$ are strong indications of the intent to place creativity as an important part of classroom teaching and learning. These reports contained a wide range of recommendations, which, amongst other issues, called for further investigations into creativity in education. Similarly, in Singapore, several educational initiatives such as the 1997 Thinking Schools Learning Nation, 2004 Teach Less Learn More, and the Twenty-First Century Competencies framework guide the implementation of creative and inventive thinking in the classroom [54]. Despite the common belief that the nurturing of creative thinking and behaviour brings benefits to the individuals and society, there seems to be challenges in fostering creativity in the classroom [55]. 
The classroom ecology that promotes creativity is complex, as it appears to require a specific school culture, and teacher pedagogical content knowledge about creativity and the pedagogical practices that are required to foster creativity. There are a few issues to be addressed before we hope teaching for creativity can take place in the classroom.

Firstly, creativity is a socially and culturally defined construct. Researchers generally agree that the nature of creativity in education remains ambiguous [7]. The definition of creativity is complex, ambiguous, and the boundary is beyond the reach of classroom teachers. In order for teaching for creativity to take place in school, the term creativity needs to be scoped in such a way that can be understood by teachers, and creativity has to be calibrated for formative and summative assessments. Although researchers conceptualize creativity as fluency, flexibility, originality, and elaboration (FFOE) [22], this is generic rather than subject domain specific. Since curriculum in school is organized by subject domains, it makes sense for there to be greater focus on including elements of creativity in each subject domain. However, there is the question of capacity, given that school subjects often gloss over the role of creativity in the learning of the discipline. Therefore, there is the issue that if teachers are ill-prepared to infuse subject-related elements of creativity into the lessons, then specific teacher-leaders will be needed who can be responsible in promoting teaching for creativity.

Secondly, educators are grappling with the issue of the 'content' of creativity-meaning what will the object of teaching for creativity entail? Historically, creativity is often connected with the creation of something new and of value. Whilst most scholars suggest creativity can be fashioned so as to yield an outcome that is of value as well as original, Craft (2000) [56] posited that it is not necessarily linked with a product-outcome, and instead offers a process-focus approach to creativity. There is also emphasis on providing opportunities for free expression, problem solving, and critical thinking [57]. The aim to teaching for creativity is developing creative thinking skills that enable pupils to generate and extend ideas, to suggest hypotheses, to apply imagination, and to look for alternative innovative outcomes [52]. According to Seltzer and Bentley (1999) [5], the learner outcomes of teaching for creativity are student ability to identify new problems, to transfer knowledge across contexts in order to solve a problem, perseverance, and the ability to focus attention in the pursuit of a goal, or set of goals. Thus, teaching for creativity in the classroom is fostering the 'little c creativity' by designing learning tasks that facilitate the creative process.

Thirdly, creativity has been recognised as a desirable aim for inclusion in the curriculum; however, creativity is often associated with teaching in early and primary school years [58,59]. Consequently, several practical strategies for fostering creativity have been documented in a large variety of early years contexts [58]. Another subject area that is associated with creativity is the Arts. Sowden, Clements, Redlich, and Lewis (2015) [60] found children who took part in the improvisation interventions showed better divergent thinking and creativity. However, there are relatively limited associations within the contexts of school subjects such as Mathematics and Science.

Fourthly, as the world is more connected with technological advancements, problems and issues we face in the 21st Century are increasingly more complex and take more than a creative individual to solve the problems [61]. Furthermore, teaching and assessing collective creativity is also different from individual creativity. Hence, teachers need the knowledge to design learning tasks that nurture individual and collective creativity.

\section{Assessing the Process for Teaching for Creativity in the Classroom}

There are many purposes, methods, instruments, and processes in assessing creativity. In school, it is useful for educators to note two ways to assess creativity, namely assessing creativity to help teaching for creativity in the classroom and assessing creativity to note the progress and outcomes of a curriculum and programme. The former is needed for teachers to assess the quality of creative thinking and the process of creativity; while the latter is useful for schools to gauge the development of the instructional programme involving the design and implementation of creativity. 
In assessing learning for creativity, however, several issues need to be addressed to lessen teachers' anxiety in teaching for creativity: (1) to delineate the boundary for the language use in the literature on terms such as 'creative teaching', 'teaching for creativity', and 'creative learning'; (2) to articulate how creativity that is culturally diverse and involving creative partnerships (e.g., policymakers and industry leaders) can be taught and assessed in classroom teaching; and (3) to outline the extent to which collective creativity is valued as against individual creativity. Addressing the aforementioned issues is the key in getting teachers to teach for creativity. Hence, if creativity is pivotal to the cognitive development of the students, then there is a need to delineate what creativity is.

Recently, Blamires and Peterson (2014) [62] reviewed the movements in teaching for creativity in the UK [63-65] and assessment literature, as well as discussing the support for teachers in developing children's creativity within the classroom. They synthesised eight enablers in fostering creativity in the classroom: (1) to design assessment activities that trigger students' imagination [66]; (2) to develop a culture for risk-taking, exploration beyond the rules, and non-conformity [63,67], and to foster a safe classroom environment where students' ideas, interests, and opinions are respected [67]; (3) to recognize the curriculum space and schedule where the teacher is a co-constructor of creative learning [7]; (4) to recognise that there is a minimum threshold of knowledge needed to be creative in any field [68]; (5) to develop creativity through collaborative and social environments with children supporting each other's creative development [68]; (6) to recognise that effective teacher education and professional development and support are needed in developing pupils' creative capacities [23]; (7) to harness technology to teach; and (8) to capitalize the necessary tools, including space, resources, and networks, in order to provide virtual and real interactive opportunities and structures for learning and teaching [69]. The implications for teaching for creativity thus emphasized the use of formative assessment strategies such as open questioning, dialogue, and feedback, as well as peer and self-assessment [66] in order to capitalize students' creative strengths which in turn inform pedagogical practice.

On the other hand, it is arguably helpful to use instruments such as Wallach-Kogan Creativity Test (WKCT) to measure generic creativity so that schools and teachers are better able to evaluate the state and progress of a curriculum or programme that aims to foster creativity [70]. Such generic assessment of creativity is difficult to score and time consuming to analyse the data. Despite the challenges, the generic analysis can provide useful indicators to note at the programmatic level to inform research and policy.

\section{The Context of the Research}

Since creativity is a function of personal background, culture and what the society values [25], and the context in which an individual resides [6], a way to achieve these desired learner outcomes is to remove the high-stakes examination. In Singapore, it is recognized that while the high-stakes examination, that is, the General Certificate of Examination Ordinary (GCE ' $\mathrm{O}^{\prime}$ ') Levels, serves as a valuable intermediate benchmark for the majority of the students, those who are academically strong can benefit from engaging in broader learning experiences during their Secondary and Junior College years. Students who successfully completed their primary school education sit for the Primary School Learning Examination (PSLE). Students with high PSLE T-scores can choose to be enrolled in the Integrated Programme (IP) which allow them to skip the GCE 'O' level examination.

In this study, all the three participating schools offer a dual programme, Express and IP, to their students. Students may choose to be enrolled into one of the programmes offered by the schools if they meet the entrance requirements. While the Express programme offers a standard curriculum and requires the students to sit for the GCE 'O' level examination at Year 4, the IP programme in each school designs and implements programmes to meet the broader learning IP goals. The design of the IP is typically based on school culture and history, as well as the curriculum leadership. Schools offering IP optimise the time freed up from preparing for the GCE ' $\mathrm{O}$ ' Levels to stretch students and provide greater breadth and depth in the academic and non-academic curricula. IP students in these schools 
receive differentiated curriculum and instruction within the core curriculum as well as enrichment programmes that run both within and out-of-class hours. The learning is typically designed to promote creative thinking and the manipulation of ideas. This study examines creativity as the outcome of two years spent in the different programmes. We see the differences in the two programmes-curriculum, instruction, and enrichment programmes (Table 1) —as affecting the development of creativity.

Table 1. Programme Features for Integrated Programme (IP) and Express.

\begin{tabular}{ccc}
\hline \multirow{2}{*}{ Features } & \multicolumn{2}{c}{ Programme } \\
\cline { 2 - 3 } & IP & Express \\
\hline High-stakes examination & $\begin{array}{c}\text { Exemption for General Certificate of } \\
\text { Education Ordinary }\left(\mathrm{GCE} \text { ' } \mathrm{O}^{\prime}\right) \text { Levels } \\
\text { Greater breadth and depth in the academic } \\
\text { and non-academic curriculum }\end{array}$ & No exemption \\
Curriculum & Differentiated for creative thinking & Standard \\
Instruction & Wider variety of enrichment programmes & Standard \\
Enrichment programmes & with some running outside school hours \\
Duration of programme & Six years & Four years \\
\hline
\end{tabular}

\section{Objectives of the Study}

Based on the above arguments, we expect that the differentiated curriculum and instruction, and the removal of the high-stakes programme in the IP programme will facilitate the development of creative potential in IP students. As students spend more time in the different programmes, we expect to see a divergence in their creative potential. This is expressed by IP students having a higher creativity mean score and showing a larger increase in creativity score from Secondary 1 to Secondary 3 than Express students.

Moreover, we are interested to find out how academic ability competes with the programme to predict creativity scores in Secondary 1 and Secondary 3 in a multiple regression. Based on Hattie (2009)'s [71] large effect size of the impact of the programme on creativity, we hypothesise that the predictive power of PSLE score on creativity would decrease over time, while that of the programme increases over time. If the data supports this hypothesis, it would support the claim that the creativity mean scores at Secondary 3 can be attributed to Programme rather than PSLE score.

Finally, although the construct of creativity consists of dimensions such as fluency, flexibility, uniqueness, and unusualness and the dimensions of creativity can be taught by using a variety of instructional strategies. Given that the nature of creativity in education is generally ambiguous and the limited strategies currently practised in the classroom, we hypothesise that it is more difficult to increase flexibility scores.

Therefore, the three hypotheses of this paper are as follows:

(1) (a) In Secondary 1 and Secondary 3, IP students will obtain higher creativity scores than Express students;

(b) From Secondary 1 to Secondary 3, IP students will show a greater increase in all measures of creativity as compared to Express students.

(2) From Secondary 1 to Secondary 3, Programme, rather than PSLE score, will increase in its ability to predict creativity scores;

(3) From Secondary 1 to Secondary 3, flexibility scores will show a small increase compared to a larger increase for fluency scores. 


\section{Methods}

\subsection{Participants}

Participants consisted of a total of 565 students from three single-gender secondary schools. Two of the schools were for females (School A, $n=165$; School B, $n=195$ ), while the third school was for males (School C, $n=205$ ). For the participants from each school, about half attended the IP programme, while the remaining attended the Express programme.

The breakdown of the student self-report PSLE score for each school and its respective programme can be seen in Table 2. Students from the IP programme had significantly higher mean PSLE scores than students from the Express programme as shown by independent $t$-tests (Table 2).

Table 2. Comparison of Primary School Leaving Examination (PSLE) score across Programme.

\begin{tabular}{ccccccccc}
\hline \multirow{2}{*}{ School } & \multicolumn{7}{c}{ IP } & \multicolumn{7}{c}{ Express } & \\
\cline { 2 - 7 } & $\boldsymbol{n}$ & $\boldsymbol{M}$ & $\boldsymbol{S D}$ & $\boldsymbol{n}$ & $\boldsymbol{M}$ & $\boldsymbol{S D}$ & $\boldsymbol{t}$ & Cohen's $\boldsymbol{d}$ \\
\hline School A & 96 & 255.3 & 3.36 & 69 & 235.7 & 10.88 & $-14.49^{* * *}$ & 2.43 \\
School B & 111 & 257.1 & 3.84 & 84 & 248.7 & 7.24 & $-10.52^{* * *}$ & 1.44 \\
School C & 81 & 252.1 & 6.15 & 124 & 241.0 & 9.06 & $-9.57^{* * *}$ & 1.43 \\
Combined & 288 & 255.1 & 4.89 & 277 & 242.0 & 10.29 & $-19.19^{* * *}$ & 1.63 \\
\hline \multicolumn{8}{c}{ Note: *** $p<0.001}$.
\end{tabular}

Two one-way between-subjects Analysis of Variance (ANOVAs) were conducted to examine if there were any differences in PSLE score related to school for both the IP and Express programmes. Results showed that there was a significant effect of school on PSLE for IP, $F(2285)=28.484, p<0.001$ and Express $F(2274)=40.959, p<0.001$ students. All Bonferroni pairwise comparisons conducted were significant at $p<0.05$ showing that the PSLE mean scores differed significantly amongst all schools for both the IP and Express students.

Nevertheless, students from these schools comprise of the top $10 \%$ of secondary students by PSLE score. This supports our decision to analyse the 565 students as a single group.

\subsection{Measures}

\subsubsection{Wallach-Kogan Creativity Test (WKCT)}

The Wallach-Kogan Creativity Test [72] is a well-known test that measures divergent thinking as a proxy of creativity. It comprises 38 items in four sections. The four sections are (a) Instances; (b) Alternate Uses; (c) Similarities; and (d) Pattern Meaning. In the test, students provide open-ended responses to questions such as "Name all the round things you can think of" and "Look at the pictures carefully, ... write your ideas and thoughts below". Students can give up to 24 responses for each question, with the instructions clearly stating that there is no right or wrong answer.

Using the work of Runco and Albert (1985) [73], the responses of the WKCT creativity are scored based on four criteria: (i) Fluency, i.e., the number of valid responses the students give; (ii) Flexibility, i.e., the number of categories their responses for a particular question falls under; (iii) Uniqueness, i.e., the number of their responses for a particular question that only appears once or twice in the pool of responses; and (iv) Unusualness, i.e., the weighted score for a number of their responses for a particular question.

Runco and Albert (1985) [73] scored statistically infrequent responses (or "original") under two indices-uniqueness and unusualness. For our study, we adopted their general method of calculating these two indices as mentioned above. Based on this general approach, we made a data driven decision to decide the cut-off for unique and unusual responses. Unique responses are responses that appear two times or less amongst the total pool of responses. Unusual responses can appear up to 
12 times, but are scored on a weighted basis, with the more statistically infrequent responses carrying a higher weight.

\subsubsection{Primary School Leaving Examination (PSLE)}

The Primary School Leaving Examination is the first national high-stakes examination that a primary school student will sit for at the end of their final year in Primary 6. Students sit for tests in four subjects-English, Chinese, Mathematics, and Science-and obtain an aggregated total score. This PSLE total score can be seen as a measure of a student's academic ability. The PSLE score is also a key consideration when secondary schools assess the students' application to join them.

\subsection{Research Design, Procedure, and Analysis}

Participating students and their parents were required to acknowledge their consent by signing on consent forms in accordance with ethics and the institutional review board. All these participants were part of another larger study that sought to understand the impact of curriculum innovation on 21st Century Competencies such as creativity, critical thinking, self-directedness, and attitudes to learning.

This was a cohort study. In the first quarter of 2013, the 565 Secondary 1 students from the three schools sat for a number of tests and surveys, one of which was the WKCT which was attempted using paper-and-pencil. Two years later in the first quarter of 2015, these same 565 students (now in Secondary 3) sat for the same tests, including the WKCT, but now in computerized format to reduce the complications and resources associated with data entry. The psychometric equivalence of the paper-and-pencil version and the computerized version of the WKCT was supported in Lau and Cheung (2010)'s [74] study using a subset of the 38 questions that were translated into Chinese. We make the assumption that the psychometric equivalence also carries over for the English version of the WKCT.

Students' responses on the WKCT were evaluated by a trained coder. Responses were accepted if they had some relevance to the question but were rejected if they were nonsensical. This evaluation was done based on a set of guidelines that were created through the team's discussion with the coder, and with close reference to actual examples of nonsensical answers.

Next, the coder collapsed responses which were conceptually similar into a single response that was representative of the idea, etc. (e.g., "car", "cars", "motorcar", "a car", "carsss" were collapsed into "car"). This was done with the use of Excel Visual Basic for Applications (Excel VBA) so the coder could filter large amounts of responses using appropriate search tools, and replace them in an accurate manner. While regular discussions were held between the coder and the research team, the coder also had to rely extensively on her own discretion because of the large number of responses and the discussed guidelines not always being applicable.

The coder also categorized responses into one of six categories that were created by the research team. These were (i) concrete; (ii) descriptive; (iii) categorical inferential; (iv) functional; (v) relational spatial; and (vi) relational temporal. These concepts were further elaborated on for each of the four different sections.

From this additional data, we were able to calculate individual scores for fluency, flexibility, uniqueness, and unusualness.

\section{Results}

Descriptive statistics and correlations for creativity dimensions for Secondary 1 (Sec. 1) and Secondary 3 (Sec. 3) are shown in Table 3. 
Table 3. Descriptive Statistics, Comparisons, and Correlation Coefficients for Creativity Dimensions over Secondary 1 (Sec. 1) and Secondary 3 (Sec. 3).

\begin{tabular}{|c|c|c|c|c|c|c|c|c|c|c|c|c|c|c|c|}
\hline Grade Level & $\begin{array}{c}\text { Dimension of } \\
\text { Creativity }\end{array}$ & $n$ & $M$ & $S D$ & $t^{\mathrm{a}}$ & $d^{\mathrm{a}}$ & PSLE & (1) & (2) & (3) & (4) & (5) & (6) & (7) & (8) \\
\hline \multicolumn{16}{|c|}{ IP Students } \\
\hline \multirow{3}{*}{ Sec. 1} & Fluency (1) & 290 & 124.94 & 38.8 & $20.85 * * *$ & 1.77 & 0.092 & - & & & & & & & \\
\hline & Uniqueness (3) & 290 & 47.45 & 28.9 & $12.00^{* * *}$ & 1.11 & 0.008 & $0.660^{* *}$ & 0.114 & - & & & & & \\
\hline & Unusualness (4) & 290 & 73.71 & 39.5 & $12.80^{* * *}$ & 1.20 & $-0.138 *$ & 0.112 & $0.483^{* *}$ & 0.035 & - & & & & \\
\hline \multirow{3}{*}{ Sec. 3} & Fluency (5) & 290 & 225.46 & 71.2 & & & 0.012 & $0.737^{* *}$ & $0.154^{* *}$ & $0.411^{* *}$ & 0.050 & - & & & \\
\hline & Flexibility (6) & 290 & 64.99 & 9.2 & & & -0.025 & $0.208^{* *}$ & $0.719 * *$ & 0.043 & $0.302 * *$ & $0.297 * *$ & - & & \\
\hline & Unusualness (8) & 290 & 159.11 & 92.4 & & & -0.020 & $0.240 * *$ & $0.792 * *$ & 0.056 & $0.346^{* *}$ & $0.283 * *$ & $0.983^{* *}$ & $0.287^{* *}$ & - \\
\hline \multicolumn{16}{|c|}{ Express Students } \\
\hline \multirow{4}{*}{ Sec. 1} & Fluency (1) & 283 & 108.82 & 40.8 & $23.99 * * *$ & 1.38 & $0.140 *$ & - & & & & & & & \\
\hline & Flexibility (2) & 283 & 53.31 & 9.2 & $12.19^{* * *}$ & 0.89 & 0.140 * & $0.441^{* *}$ & - & & & & & & \\
\hline & Uniqueness (3) & 283 & 37.96 & 31.2 & $15.23 * * *$ & 0.88 & $0.127 *$ & $0.808^{* *}$ & $0.394 * *$ & - & & & & & \\
\hline & Unusualness (4) & 283 & 60.43 & 42.2 & $16.45^{* * *}$ & 0.94 & 0.088 & $0.211 * *$ & $0.325^{* *}$ & $0.224^{* *}$ & - & & & & \\
\hline \multirow{3}{*}{ Sec. 3} & Fluency (5) & 283 & 190.59 & 72.9 & & & $0.134^{*}$ & $0.776^{* *}$ & $0.271^{* *}$ & $0.600^{* *}$ & 0.085 & - & & & \\
\hline & Flexibility (6) & 283 & 61.71 & 9.6 & & & 0.099 & $0.288^{* *}$ & $0.732 * *$ & 0.248 ** & $0.196^{* *}$ & $0.282 * *$ & - & & \\
\hline & Uniqueness (7) & 283 & 80.5 & 60.4 & & & $0.143 *$ & $0.851^{* *}$ & $0.301 * *$ & $0.666 * *$ & 0.113 & $0.979 * *$ & $0.286^{* *}$ & - & \\
\hline
\end{tabular}


8.1. Hypothesis 1a: In Secondary 1 and Secondary 3, IP Students Will Obtain Higher Creativity Scores Than Express Students

Two sets of four independent $t$-tests were conducted to compare creativity scores of IP students to Express students in both Secondary 1 and Secondary 3. Results from the t-tests supported the hypothesis. IP students scored significantly higher than Express students in all four measures of creativity both in Secondary 1 ( $p<0.001$, and effect sizes, $d$, ranging from $d=0.27$ to $d=0.40)$ and Secondary 3 ( $p<0.001, d$, ranging from $0.35<d<0.48)$ (Table 4 ).

Table 4. Comparison of IP and Express Programmes for Creativity Dimensions.

\begin{tabular}{|c|c|c|c|c|}
\hline \multirow{3}{*}{$\begin{array}{c}\text { Dimension of } \\
\text { Creativity }\end{array}$} & \multicolumn{4}{|c|}{ Grade Level } \\
\hline & \multicolumn{2}{|c|}{ Sec. 1} & \multicolumn{2}{|c|}{ Sec. 3} \\
\hline & $t$ & $d$ & $t$ & $d$ \\
\hline Fluency & $4.85^{* * *}$ & 0.40 & $5.79 * * *$ & 0.48 \\
\hline Flexibility & $3.20 * *$ & 0.27 & $4.17^{* * *}$ & 0.35 \\
\hline Uniqueness & $3.78^{* * *}$ & 0.32 & $4.80^{* * *}$ & 0.40 \\
\hline Unusualness & $3.89 * * *$ & 0.33 & $5.00 * * *$ & 0.42 \\
\hline
\end{tabular}

8.2. Hypothesis 1b: From Secondary 1 to Secondary 3, IP Students Will Show a Greater Increase in All Measures of Creativity as Compared to Express Students.

Two sets of four paired $t$-tests were conducted to investigate if creativity scores changed significantly over time for both Express and IP students (Table 3). Results from the $t$-tests supported this hypothesis. While IP students showed an increase of $d=1.77$ for their fluency score, Express students lagged behind with an increase of $d=1.38$. This pattern holds for flexibility, uniqueness, and unusualness, though to a lesser extent.

8.3. Hypothesis 2: From Secondary 1 to Secondary 3, the Programmes, Rather than PSLE Score, Increases in its Ability to Predict Creativity Scores

Eight multiple regressions were conducted with Fluency, Flexibility, Uniqueness, and Unusualness with Secondary 1 and Secondary 3 each as a dependent variable. The two independent variables were PSLE score and Programme. Multicollinearity was not an issue as the variance inflation factor (VIF) was below 4 [75] for all the predictor variables. The results of the regression are shown in Table 5. At Secondary 1, PSLE score was a significant predictor for Fluency $(\beta=0.17, p=0.002)$ while Programme was not a significant predictor $(\beta=0.09, p=0.095)$. However, the relationship was reversed at Secondary 3; PSLE score was no longer a significant predictor for Fluency $(\beta=0.05, p=0.320)$, but Programme was $(\beta=0.2, p<0.001)$. This pattern was also seen for the other creativity measures of Flexibility, Uniqueness, and Unusualness. Therefore, the results from the multiple regression strongly support the hypothesis that programme becomes a better predictor of creativity scores as students progress from Secondary 1 to Secondary 3.

Table 5. Multiple Regression Prediction of Creativity Scores at Secondary 1 and Secondary 3.

\begin{tabular}{lccccc}
\hline Predictor & $\boldsymbol{B}$ & $\boldsymbol{S E} \boldsymbol{B}$ & $\boldsymbol{\beta}$ & $\boldsymbol{T}$ & $\boldsymbol{R}^{2}$ \\
\hline \multicolumn{5}{c}{ Fluency } \\
\hline Sec. 1 & & & & \\
$\quad$ PSLE & 0.647 & 0.21 & 0.17 & $3.103^{* *}$ & 0.053 \\
$\quad$ Programme & 7.2 & 4.31 & 0.09 & 1.672 & \\
Sec. 3 & & & & & 0.057 \\
$\quad$ PSLE & 0.377 & 0.38 & 0.05 & 0.995 & \\
$\quad$ Programme & 29.87 & 7.84 & 0.2 & $3.811^{* * *}$ & \\
\hline
\end{tabular}


Table 5. Cont.

\begin{tabular}{|c|c|c|c|c|c|}
\hline Predictor & $B$ & $S E B$ & $\beta$ & $T$ & $R^{2}$ \\
\hline \multicolumn{6}{|c|}{ Flexibility } \\
\hline Sec. 1 & & & & & 0.026 \\
\hline PSLE & 0.111 & 0.05 & 0.12 & 2.293 * & \\
\hline Programme & 1.001 & 1 & 0.05 & 0.998 & \\
\hline Sec. 3 & & & & & 0.029 \\
\hline PSLE & 0.018 & 0.05 & 0.02 & 0.359 & \\
\hline Programme & 3.024 & 1.02 & 0.16 & $2.952 * *$ & \\
\hline \multicolumn{6}{|c|}{ Uniqueness } \\
\hline Sec. 1 & & & & & 0.033 \\
\hline PSLE & 0.375 & 0.16 & 0.13 & 2.374 * & \\
\hline Programme & 4.396 & 3.27 & 0.07 & 1.345 & \\
\hline Sec. 3 & & & & & 0.038 \\
\hline PSLE & 0.238 & 0.35 & 0.04 & 0.689 & \\
\hline Programme & 22.65 & 7.13 & 0.17 & $3.178 * *$ & \\
\hline \multicolumn{6}{|c|}{ Unusualness } \\
\hline Sec. 1 & & & & & 0.036 \\
\hline PSLE & 0.541 & 0.22 & 0.14 & 2.523 * & \\
\hline Programme & 5.949 & 4.43 & 0.07 & 1.342 & \\
\hline Sec. 3 & & & & & 0.041 \\
\hline PSLE & 0.252 & 0.46 & 0.03 & 0.543 & \\
\hline Programme & 32.93 & 9.59 & 0.18 & $3.435^{* *}$ & \\
\hline
\end{tabular}

8.4. Hypothesis 3: From Secondary 1 to Secondary 3, Flexibility Scores Show a Smaller Increase Compared to Fluency Scores

As seen from the magnitude of change of flexibility and fluency scores, this hypothesis was also supported. Flexibility scores increased to a smaller extent compared to fluency scores when examining the change over time as measured by effect size (for IP, $d=0.99$ vs. 1.77 and for Express, $d=0.89$ vs. 1.38 in Table 3). Examining the raw scores reveal stronger support for this hypothesis. For both IP and Express students, the raw score for fluency almost doubled over time; however, the raw score for flexibility only increased by about $20 \%$.

\section{Discussion and Implications}

\subsection{Comparisons of Creativity Scores Between Groups}

Creativity is one of the desired student learning outcomes for both Express and IP. Hattie (2009) [71] reported creativity programme yields an effect size of 0.69 and problem solving teaching has an effect size of 0.63. Moreover, Rogers's (1991, 2002, 2007) [76-78] meta-synthesis studies showed that high ability learners need daily challenge in their specific areas of talent in order to develop their talents. In her study, the effect sizes for cluster grouping with specific differentiation and enriched classes ability groups are both 0.33 ; regrouping for specific instruction in reading and Mathematics is 0.34 . The effect sizes in our analyses are more nuanced than the meta-studies reported by Hattie and Rogers. The same cohort of high ability students scored statistically higher than Express students when they were in Secondary 1 and Secondary 3. The effect sizes range from 0.27 to 0.40 for Flexibility and Fluency, respectively, at Time 1. At Time 2, the effect sizes increased to 0.35 to 0.48 for Flexibility and Fluency, respectively. Such nuanced empirical evidence is useful for instructional design in the classroom.

One of the challenges in providing intellectual stimulation to high ability learners is the difficulties to differentiate curriculum and instruction within the curriculum time. Most programmes for high 
ability students enriched learning through out-of-class enrichment. While such programmes yield desirable effect sizes as reported by Hattie, there is a lack of concerted effort in differentiating the core curriculum where the learning of high ability learners are not maximized. Our findings, however, demonstrated that even at the initial stage of differentiating curriculum and instruction based on the core curriculum, with concerted efforts across subjects, yields a larger effect size compared to subject-specific instruction reported by Rogers's $(1991,2002,2007)$ [76-78] meta-analysis. Differentiating curriculum and instruction based on the core curriculum does not require teachers and students to spend time after school. Thus, it is a more sustainable approach in providing intellectual challenges to high ability students. This is a significant finding to shift the practice of providing out-of-class enrichment as the only means to challenge high ability students.

By comparing the two groups, we document the magnitude of change between the groups. Although these findings showed that creativity increases regardless of the programme the students enrolled in, students enrolled in the IP showed higher gain scores as compared to those enrolled in the Express programme. This suggests that the approach in which the school designs and implements the IP might be one of the contributing factors to the gain scores in creativity. These findings imply the time given for nurturing broader learning is a way to allow schools to provide a learning environment that fosters creativity.

\subsection{Predictors of Creativity Scores and the Influence of Programme in the Context}

Performativity, such as the high-stakes examination features in the educational system, tends to take the blame for killing creativity in learning and teaching [11]. One might argue that there is limited scope to develop the creative potential of students in a system with high-stakes examination requirements. In this study, we tested whether PSLE and Programme are good predictors of creativity score over time. Since the creativity scores for students enrolled in the IP is statistically significant, there is a need to investigate whether the differences between students enrolled in Express and IP are due to the ability of the students or the input of the programmes. In our analysis, the PSLE score emerged to be a significant predictor for Fluency when the students were at Secondary 1 whereas Programme emerged as the predictor for Fluency when the cohort of students was at Secondary 3. Thus, over time, programme becomes a better predictor of creativity scores than PSLE. These findings suggest that the gain scores for students who enrolled in the IP are due to the programme rather than PSLE achievement.

This pattern was also present for the other creativity measures of Flexibility, Uniqueness, and Unusualness. Therefore, the results of this study strongly support the hypothesis that programme becomes a better predictor of creativity scores as students progress from Secondary 1 to Secondary 3 . These findings imply that classroom contexts matter in fostering creativity among students. Drawing from Blamires and Peterson's (2014) [62] argument on pedagogic strategies as an enabler for creativity, it is important to have clarity in how creativity looks like in specific subject domains and the associated skills. This is so teachers can design learning tasks and scaffolding to create conditions which support creative processes and behaviours. In addition, Troman et al. (2007) [43] argue that if creativity is being valued in the educational policy, teachers can raise pupil test scores by involving both performative and creative strategies as the creativity and performativity policies are viewed as means to raising educational standards in schools. As such, the implementation of creativity and performativity policies provided contextual influencing factors on teacher commitment in teaching for creativity.

\subsection{Change in Dimensions of Creativity}

As the nature of creativity in education remains ambiguous [7], the extent to which teachers can design the lessons to facilitate the growth of creativity is unknown. Torrance (1970) [37] and other scholars in creativity literature view creativity in four dimensions, namely fluency, flexibility, originality, and elaboration (FFOE). The National Advisory Committee on Creative and Cultural Education (1999) [68] suggests the creative process involves defining the purpose, originality, and 
value of creative acts and processes. Blamires and Peterson (2014) [62] further argued that the creative process takes place within subject disciplines as creativity requires knowledge and skills to provide it with a purpose. The implication is that nurturing of creativity is dependent on pedagogy and that different pedagogy within different subject domains may foster or hinder creativity.

Since teaching for creativity is dependent on pedagogy, we believe that there will be variation in different dimensions of creativity. We argue that flexibility score is more difficult to change. In examining the rate of growth over time in the creativity dimensions, our findings suggest that flexibility scores are more resistant to change compared to fluency scores. Flexibility scores increase to a smaller extent compared to fluency scores when examining the change over time as measured by effect size. Examining the raw scores reveal stronger support for this hypothesis. For both IP and Express students, the raw score for fluency almost doubled over time; however, the raw score for flexibility only increased by about $20 \%$. With that said, our investigation is generic, not subject-specific and aims to identify whether there are changes in creativity dimensions between students who enrolled in the IP as compared to those who enrolled in the Express. The implication of these findings is that teaching for creativity can be focused by making learning objectives clear in the respective creativity dimensions. This would enable teachers to reap the results of teaching for creativity. In particular, teaching for flexibility requires teachers to shift their practice by introducing different ideas from diverse domains of knowledge and skills, rather than more of the same domain.

\subsection{Implications}

There are several noteworthy implications of our findings that contribute to the body of research on creativity. Firstly, few studies document the growth of creativity in the context of differentiating the core curriculum. We have empirically documented the significant outcomes of creativity through a concerted effort in differentiating curriculum and instruction. Our findings thus demonstrated the importance of taking classroom context into account when discussing the nurturing of creativity of high ability students. Secondly, in examining the different dimensions of creativity, we identified the resistance of flexibility score to change. This nuanced understanding of nurturing creativity is informative to researchers and practitioners. We have reason to teach by using a variety of instructional strategies and to discuss different categories of ideas in order to deliberately stretch students to think flexibly (i.e., achieving mental agility). Thirdly, our attempt in documenting creativity scores over time is the strength of the design. Given the different learning capacity of the Express and IP students, measuring creativity twice allows the study to examine whether the programme is a good predictor.

Overall, this study provides empirical evidence to ascertain how curriculum and instruction incorporated spaces for creative thinking could make a difference in the quality of learning that is very much desired in the 21st century classrooms. Moreover, differentiating curriculum and instruction could emphasize different dimensions of creativity in maximizing learning. As such, the nature of creativity in education does not have to be ambiguous [6] and creativity can be taught within the knowledge and skills of subject domains [62].

\subsection{Limitations of the Study}

There are several limitations that should be noted. First, the IP and Express students differ significantly in terms of their PSLE scores. While it is hard, if not impossible, to find students from the two programmes with similar PSLE scores, we have controlled for this by including PSLE score as a predictor variable in the regression. The results support the conclusion that Programme plays an important role regarding creativity scores.

Next, we only had one coder to score the answers because of project constraints. This might result in some slight inaccuracies in the different creativity scores as there was no second coder to verify the scoring of answers. However, the impact on the results is mitigated because any coding inaccuracies applies equally to the Express and IP programmes and will not lead to exaggerated group differences. 
Third, the calculation of the creativity measures-fluency, flexibility, uniqueness, and unusualness-leads to very high correlation between the measures. The more answers a student gives (fluency), the more answers there are available to be marked as being from different categories or as statistically rare. This is an artefact of the calculation process. Nevertheless, the flexibility, uniqueness, and unusualness measures are derived from separate coding processes and are valid measures that contribute unique variance.

Finally, since the WKCT does not measure domain-specific creativity, we are unable to comment on how the different programmes affect the development of creativity at the subject level. However, our findings do suggest that the classroom context matters and that the removal of high-stakes examination can provide room for the development of creative potential. Further classroom observations and analyses will be needed to understand the impact on creativity in different subject domains.

\section{Conclusions}

Teaching for creativity needs greater understanding and evidence more than a psychological construct of creativity. Taking together the findings in this study, conceptualising and implementing teaching for creativity have to take into consideration all the four Ps, that is, the person, process, product, and press (i.e., environment). In particular, the learning environment and context is an important variable in contributing to the nurturing of creativity within subject-domain. Moreover, clarity in designing learning tasks that is specific to fostering different dimensions of creativity yield different gain scores. Hence, a deliberate effort in designing curriculum and using pedagogy to elicit creative thinking, behaviours, and actions in the classroom is the key in teaching for creativity. Our study demonstrates that giving schools a mandate to differentiate curriculum and instruction for high ability students by removing one of the high-stakes examinations result in a favourable learning environment for fostering creativity among students.

Acknowledgments: This study was funded by the Education Research Funding Programme, National Institute of Education, Nanyang Technological University, Singapore. Project number OER54/12TLS.

Author Contributions: Liang See Tan is the Principal Investigator of the project. She conceptualized this paper and lead the writing of this paper; Shu Shing Lee, Letchmi Devi Ponnusamy and Elizabeth Koh are the Co-Principal Investigators in this project and they were involved in data collection, discussion, analysis and provide inputs for the writing of this paper; Keith Tan Chiu Kian is the lead researcher in analyzing the data and wrote the findings section of this paper.

Conflicts of Interest: The authors declare no conflict of interest.

\section{References}

1. Florida, R. The Rise of the Creative Class: And How It's Transforming Work, Leisure, Community, and Everyday Life; Basic Books: New York, NY, USA, 2004.

2. Beghetto, R.A.; Kaufman, J.C. (Eds.) Nurturing Creativity in the Classroom; Cambridge University Press: New York, NY, USA, 2010.

3. Tishman, S.; Perkins, D.; Jay, E. Introduction: The Idea of a Culture of Thinking. The Thinking Classroom: Learning and Teaching in a Culture of Thinking; Allyn \& Bacon: Boston, MA, USA, 1995; pp. 1-6.

4. Voogt, J.; Roblin, N.P. A Comparative Analysis of International Frameworks for 21st Century Competencies: Implications for National Curriculum Policies. J. Curriculum Stud. 2012, 44, 299-321. [CrossRef]

5. Seltzer, K.; Bentley, T. The Creative Age: Knowledge and Skills for the New Economy; Demos: London, UK, 1999.

6. Craft, A. The Limits to Creativity in Education: Dilemmas for the Educator. Br. J. Educ. Stud. 2003, 51, 113-127. [CrossRef]

7. Craft, A. Creativity in Schools: Tensions and Dilemmas; Routledge: London, UK, 2005.

8. Craft, A.; Jeffrey, B. Creativity and Performativity in Teaching and Learning: Tensions, Dilemmas, Constraints, Accommodations and Synthesis. Br. J. Educ. Stud. 2008, 34, 577-584. [CrossRef]

9. Saravanan, V. 'Thinking Schools, Learning Nations' Implementation of Curriculum Review in Singapore. Educ. Res. Policy Pract. 2005, 4, 97-113. [CrossRef] 
10. Mumford, M. Where Have we Been, Where are we Going? Taking Stock in Creativity Research. Creat. Res. J. 2003, 5, 107-120. [CrossRef]

11. Robinson, K. Out of your Minds: Learning to be Creative, 2nd ed.; Courier Westford, Inc.: Westford, MA, USA, 2011.

12. Nakakoji, K.; Yamamoto, Y.; Ohira, M. A Framework that Supports Collective Creativity in Design using Visual Images. In Proceedings of the 3rd Conference on Creativity and Cognition, Loughborough, UK, 11-13 October 1999; pp. 166-173.

13. Strom, R.D.; Strom, P.S. Changing the Rules: Education for Creative Thinking. J. Creat. Behav. 2002, 36, 183-200. [CrossRef]

14. Plucker, J.A.; Beghetto, R.A.; Dow, G.T. Why isn't Creativity More Important to Educational Psychologists? Potentials, Pitfalls, and Future Directions in Creativity Research. Educ. Psychol. 2004, 39, 83-96. [CrossRef]

15. Getzels, J.W.; Cziksentmihalyi, M. The Creative Vision: A Longitudinal Study of Problem-solving in Art; Wiley: New York, NY, USA, 1976.

16. Simonton, D.K. Genius, Creativity and Leadership: Historiometric Enquiries; Harvard University Press: Cambridge, MA, UK, 1984.

17. Simonton, D.K. Creativity in Science: Chance, Logic, Genius, and Zeitgeist; Cambridge University Press: Oxford, UK, 2004.

18. Guiford, J.P. Creativity. Am. Psychol. 1950, 5, 444-445. [CrossRef]

19. Guiford, J.P. The Nature of Human Intelligence; McGraw-Hill: New York, NY, USA, 1967.

20. Wallas, G. The Art of Thought; Harcourt-Brace: New York, NY, USA, 1926.

21. Sternberg, R.J. A Three-Facet Model of Creativity. In The Nature of Creativity; Sternberg, R.J., Ed.; Cambridge University Press: Cambridge, UK, 1988.

22. Torrance, E.P. Torrance Tests of Creativity; Personnel Press: Princeton, NJ, USA, 1966.

23. Jeffrey, B.; Craft, A. Teaching Creatively and Teaching for Creativity: Distinctions and Relationships. Educ. Stud. 2004, 30, 77-87. [CrossRef]

24. Ryhammar, L.; Brolin, C. Creativity Research: Historical Considerations and Main Lines of Development. Scan. J. Educ. Res. 1999, 43, 259-273. [CrossRef]

25. Csikszentmihalyi, M. Implications of a Systems Perspective for the Study of Creativity. In Handbook of Creativity; Sternberg, R.J., Ed.; Cambridge University Press: Cambridge, UK, 1999; pp. 313-335.

26. Sternberg, R.J.; Lubart, T.I. The Conception of Creativity: Prospects and Paradigms. In Handbook of Creativity; Sternberg, R.J., Ed.; Cambridge University Press: Cambridge, UK, 1999; pp. 3-15.

27. Lubart, T.I. Creativity across Cultures. In Handbook of Creativity; Sternberg, R.J., Ed.; Cambridge University Press: Cambridge, UK, 1999; pp. 339-350.

28. Collins, M.A.; Ambabile, T.M. Motivation and Creativity. In Handbook of Creativity; Staw, B.M., Cunnings, L.L., Eds.; Cambridge University Press: Cambridge, UK, 1999; pp. 297-312.

29. Amabile, T.M. A Model of Creativity and Innovation in Organisations. In Research in Organisational Behaviour; JAI Press: Greenwich, London, UK, 1988.

30. Torrance, E.P. A Longitudinal Examiniation of the Fourth-grade Slump in Creativity. Gifted Child Quart. 1968, 12, 195-199.

31. Urban, K.K. On the Development of Creativity in Children. Creat. Res. J. 1991, 4, 177-191. [CrossRef]

32. Camp, G.C. A Longitudinal Study of Correlates of Creativity. Creat. Res. J. 1994, 7, 125-144. [CrossRef]

33. Rosenblatt, E.; Winner, E. The Art of Children's Drawings. J. Aesthet. Educ. 1988, 22, 3-15. [CrossRef]

34. Smith, G.J.W.; Carlsson, I. Creativity in Middle and Late School Years. Int. J. Behav. Dev. 1985, 8, 329-343. [CrossRef]

35. Runco, M.A.; Charles, R.E. Developmental Trends in Creative Potential and Performance. In The Creativity Research Handbook; Runco, M.A., Ed.; Hampton: Cresskill, NJ, USA, 1997; pp. 115-154.

36. Beghetto, R.A.; Kaufman, J.C. Classroom Contexts for Creativity. High Abil. Stud. 2014, 25, 53-69. [CrossRef]

37. Torrance, E.P. Encouraging Creativity in the Classroom; William C. Brown Company: Dubuque, IA, USA, 1970.

38. Torrance, E.P.; Gupta, R.K. Programmed Experiences in Creativity Thinking; University of Minnesota, Bureau of Educational Research: Minneapolis, MI, USA, 1964.

39. Csikszentmihalyi, M. Flow: The Psychology of Optimal Experience; Harper and Row: New York, NY, USA, 1990.

40. Berliner, D.C. Rational Responses to High Stakes Testing: The Case of Curriuclum Narrowing and the Harm that Follows. Camb. J. Educ. 2011, 41, 287-302. [CrossRef] 
41. Davies, D.; Jindal-Snape, D.; Collier, C.; Digby, R.; Hay, P.; Howe, A. Creative Learning Environments in Education: A Systematic Literature Review. Think. Skills Creat. 2012, 8, 80-91. [CrossRef]

42. Beghetto, R.A.; Kaufman, J.C. Teaching for Creativity with Disciplined Improvisation. In Structure and Improvisation in Creative Teaching; Sawyer, R.K., Ed.; Cambridge University Press: Cambridge, UK, 2011; pp. 94-109.

43. Troman, G.; Jeffrey, B.; Raggl, A. Creativity and Performativity Policies in Primary School Cultures. J. Educ. Policy 2007, 22, 549-572. [CrossRef]

44. Cox, C.B.; Dyson, A.E. The Black Papers on Education: A revised edition; Davis-Poynter: London, UK, 1971.

45. Woods, P.; Jeffrey, B. Teachable Moments: The Art of Teaching in Primary Schools; Open University Press: Buckingham, UK, 1996.

46. Craft, A. Nourishing Educator Creativity: A Holistic Approach to CPD. J. Serv. Educ. 1996, 22, $309-322$. [CrossRef]

47. Fryer, M. Creative Teaching and Learning; Paul Chapman: London, UK, 1996.

48. Sawyer, R.K. Creative Teaching: Collaborative Discussion as Disciplined Improvisation. Educ. Res. 2004, 33, 12-20. [CrossRef]

49. Nolan, V. Creativity: The Antidote to the Argument Culture. In Creativity and Cultural Diversity; Fryer, M., Ed.; The Creativity Centre Educational Trust: Leeds, UK, 2004.

50. Treffinger, D.J.; Isaksen, S.G. Creative Problem Solving: The History, Development, and Implications for Gifted Education and Talent Development. Gifted Child Quart. 2005, 49, 342-353. [CrossRef]

51. Plowden, B. Children and Their Primary Schools: A Report of the Control Advisory Council for Education (England). Available online: http://www.educationengland.org.uk/documents/plowden/plowden19671.html (accessed on 5 September 2016).

52. Department for Education and Employment. The National Curriculum: Handbook for Primary Teachers in English. Available online: http://www.educationengland.org.uk/documents/pdfs/1999-nc-primaryhandbook.pdf (accessed on 5 September 2016).

53. UK Parliamentary Business. Select Committee on Education and Skills Third Report: Currciulum 2000. Available online: http://www.publications.parliament.uk/pa/cm200203/cmselect/cmeduski/153/15306.htm (accessed on 5 September 2016).

54. Ministry of Education, Singapore. 21st Century Competencies. Available online: https://www.moe.gov.sg/ education/education-system/21st-century-competencies (accessed on 5 September 2016).

55. Cropley, A. Fostering Creativity in the Classroom: General Principles. In The Creativity Research Handbook; Runco, M.A., Ed.; Hampton Press: Cresskill, NJ, USA, 1997; Volume 1, pp. 83-114.

56. Craft, A. Creativity across the Primary Curriculum; Routledge: London, UK, 2000.

57. National Foundation for Educational Research (NFER). CAPE UK: Stage One Evaluation Report. Available online: https:/ / www.nfer.ac.uk/publications/91012/91012.pdf (accessed on 5 September 2016).

58. Beetlestone, F. Learning in the Early Years: Creative Development; Scholastic: Leamington Spa, UK, 1998.

59. Desailly, J. Creativity in the Primary Classroom; Sage: London, UK, 2012.

60. Sowden, P.T.; Clements, L.; Redlich, C.; Lewis, C. Improvisation Facilitates Divergent Thinking and Creativity: Realizing a Benefit of Primary School Arts Education. Psychol. Aesthet. Creat. Arts 2015, 9, 128. [CrossRef]

61. Catmull, E. How Pixar Fosters Collective Creativity. Harvard Business Review. Available online: https://hbr.org/2008/09/how-pixar-fosters-collective-creativity (accessed on 5 September 2016).

62. Blamires, M.; Peterson, A. Can Creativity be Assessed? Towards an Evidence-informed Framework for Assessing and Planning Progress in Creativity. Camb. J. Educ. 2014, 44, 147-162. [CrossRef]

63. Office for Standards in Education. Expect the Unexpected: Developing Creativity in Primary and Secondary Schools. Available online: http://dera.ioe.ac.uk/4766/1/Expecting_the_unexpected_(PDF_format).pdf (accessed on 5 September 2016).

64. Office for Standards in Education. Creative Partnerships: Initiative and Impact. Available online: http:// www.creativitycultureeducation.org/wp-content/uploads/ofsted-creative-partnerships-report-15-15.pdf (accessed on 5 September 2016).

65. Office for Standards in Education. Learning: Creative Approaches that Raise Standards. Available online: http:/ /www.creativitycultureeducation.org/wp-content/uploads/learning-creative-approachesthat-raise-standards-250.pdf (accessed on 5 September 2016). 
66. Black, P.; Wiliam, D. Developing a Theory of Formative Assessment. In Assessment and Learning; Gardner, J., Ed.; Sage: London, UK, 2006; pp. 143-181.

67. Qualifications and Curriculum Authority. Creativity: Find it, Promote it-Promoting pupils' Creative Thinking and Behaviour across the Curriculum at Key Stages 1, 2 and 3-Practical Materials for Schools. Available online: https:/ /www.literacyshed.com/uploads/1/2/5/7/12572836/1847211003.pdf (accessed on 5 September 2016).

68. National Advisory Committee on Creative and Cultural Education. All our Futures: Creativity, Culture and Education. Available online: http://www.creativitycultureeducation.org/all-our-futures-creativity-cultureand-education (accessed on 5 September 2016).

69. Loveless, A.M. Creativity, Technology and Learning-A Review of Recent Literature. Available online: http:/ / citeseerx.ist.psu.edu/viewdoc/download?doi=10.1.1.392.2297\&rep=rep1\&type=pdf (accessed on 5 September 2016).

70. Soland, J.; Hamilton, L.S.; Stecher, B.M. Measuring 21st Century Competencies: Guidance for Educators. Available online: http:/ /asiasociety.org/files/gcen-measuring21cskills.pdf (accessed on 5 September 2016).

71. Hattie, J. Visible Learning: A Synthesis of over 800 Meta-analyses Relating to Achievement; Routledge: London, UK, 2009.

72. Wallach, M.A.; Kogan, N. Modes of Thinking in Young Children: A Study of the Creativity Intelligence Distinction; Holt, Rinehart \& Winston: New York, NY, USA, 1965.

73. Runco, M.A.; Albert, R.S. The Reliability and Validity of Ideational Originality in the Divergent Thinking of Academically Gifted and Nongifted Children. Educ. Psychol. Meas. 1985, 45, 483-501.

74. Lau, S.; Cheung, P.C. Creativity Assessment: Comparability of the Electronic and Paper-and-Pencil Versions of the Wallach-Kogan Creativity Tests. Think. Skills Creat. 2010, 5, 101-107. [CrossRef]

75. Cohen, J.; Cohen, P.; West, S.G.; Aiken, L.S. Applied Multiple Regression/Correlation Analysis for the Behavioral Sciences, 3rd ed.; Lawrence Erlbaum Associates: Mahwah, NJ, USA, 2003.

76. Rogers, K.B. The Relationship of Grouping Practices to the Education of the Gifted and Talented Learner. Available online: https://login.libproxy.nie.edu.sg/login?url=http://search.ebscohost.com/login.aspx? direct $=$ true\&db=eric\&AN=ED343330\&site=ehost-live\&scope=site (accessed on 5 September 2016).

77. Rogers, K.B. Grouping the Gifted and Talented: Questions and Answers. Roeper Rev. 1993, 16, 8-12. [CrossRef]

78. Rogers, K.B. Lessons Learned about Educating the Gifted and Talented: A Synthesis of the Research on Educational Practice. Gifted Child Quart. 2007, 51, 382-396. [CrossRef] 